\title{
AN ECONOMIC JUSTIFICATION FOR THE EKS MULTILATERAL INDEX
}

\author{
BY KEVIN J. FOX* \\ The University of New South Wales
}

\begin{abstract}
A justification for the use of the EKS multilateral index can be given from the economic approach to index numbers.
\end{abstract}

\section{INTRODUCTION}

Multilateral index numbers are used for price, output, input and productivity comparisons across economic entities, such as countries. They statisfy a circularity (transitivity) requirement so that the same result is achieved if countries are compared with each other directly, or with each other through their relationships with other countries. ${ }^{1}$ Standard (bilateral) index-number formulae do not satisfy this circularity requirement. This has led to a large variety of alternative techniques being suggested for making international comparisons (Hill, 1997). For example, the Penn World Tables, which are derived from the UN International Comparison Program (ICP) (Kravis et al., 1978), effectively use the Geary-Khamis method (Geary, 1958; Khamis, 1972) in order to make transitive multilateral comparisons. Data from this source have been widely used in recent research, although "few of those who used them know their origin or ever examine the methods underlying the original expenditure and price measures" (Heston and Lipsey, 1999). However, concerns have been expressed regarding the properties of the Geary-Khamis method (Dowrick and Quiggin, 1997; Diewert, 1999; Caves et al., 1982).

The performance of bilateral index numbers is typically assessed using two alternative methods. Specifically, the axiomatic approach and the economic approach. The axiomatic approach evaluates an index-number formula by how many "reasonable" axioms it satisfies (Walsh, 1901, 1921, 1924; Fisher, 1922). This approach, based on checking an index number against a list of desirable mathematical properties, is often considered to be too mechanical and unrelated to economics. The economic approach evaluates an index-number formula on the basis of the functional form of an aggregator function from which it can be derived (Konüs, 1924). This is known as the "exact" relationship between the indexnumber formula and the aggregator function. The more general the properties of

Note: Helpful comments from an anonymous referee, Erwin Diewert, Robert Hill and Glenn Otto are gratefully acknowledged. The usual disclaimer applies.

*Correspondence to: Kevin J. Fox, School of Economics and Centre for Applied Economic Research, The University of New South Wales, Sydney, NSW 2052, Australia (K.Fox@unsw.edu.au).

${ }^{1}$ The circularity property is desirable in a number of multilateral comparison contexts. See, for example, Proposition 1 of Aczél (1990). 
the functional form in terms of the technology that it can represent, the stronger the theoretical justification for the corresponding index-number formula. If the aggregator function has the property of flexibility ${ }^{2}$ then the corresponding index-number formula is called superlative (Diewert, 1976). Examples of superlative index-number formulae include the Fisher Ideal index (Fisher, 1922) and the Törnqvist index (Törnqvist, 1936).

The EKS multilateral index (Eltetö and Köves, 1964; Szulc, 1964) is based on the use of the bilateral Fisher Ideal index. ${ }^{3}$ Caves, Christensen, and Diewert (1982) (CCD), while introducing the translog multilateral index (based on the Törnqvist index), made favorable comment about the attractive properties of the EKS method. However, they were unable to provide a theoretical justification for its use from the economic approach to index numbers that matched the justification they gave for the use of the translog multilateral index:

It is not known whether the EKS can be derived directly from a flexible transformation function that is non-separable in inputs and outputs and permits non-neutral differences in productivity among countries. (Caves et al., 1982, p. 83)

Further, they note the following in footnote 1 on the same page:

It is straightforward to derive the EKS index in the separable, neutral case, but we have not succeeded in deriving EKS in the general case.

However, they were able to set out in a systematic fashion an economic justification for the translog multilateral index (Caves et al., 1981), based on results for the bilateral translog (Törnqvist) index from Diewert (1976). ${ }^{4}$ The CCD paper has popularized the use of the translog multilateral index to the extent that it is commonly referred to as the "CCD index." More importantly, it has often relegated the EKS index to the relative obscurity of footnotes (e.g., Pilat and Rao, 1996, p. 119), in spite of the favorable comments by CCD concerning this index. Although the EKS index is popular for multilateral comparisons in consumer contexts, Coelli et al. (1998, p. 86) noted that in producer contexts the CCD index "is the form used in most empirical analyses of total factor productivity measurement conducted during the past decade." This seems to be because the EKS method has not been shown to be as well founded in economic theory as the CCD index (Neary, 2000, p. 5), as the CCD index has been shown to have an exact relationship with a more general functional form than could be shown for the EKS index (Caves et al., 1982). Hence, the CCD index is currently regarded as having a much stronger justification than the EKS index.

\footnotetext{
${ }^{2} \mathrm{~A}$ functional form is "flexible" if it can theoretically approximate an arbitrary twice continuously differentiable, linearly homogeneous function to the second order at a point (Diewert, 1976).

${ }^{3}$ Some authors use the term "EKS" to refer to the method of making any bilateral index transitive, whereas here the more common usage is employed so that it refers to the multilateral index based on the bilateral Fisher index.

${ }^{4}$ In doing so, they addressed the well known trade-off between "characteristicity" and circularity (Dreschler, 1973). Characteristicity refers to "the degree to which weights are specific to the comparison at hand" (Caves et al., 1982, p. 74). Dreschler (1973, p. 17) noted that ". . . characteristicity and circularity are always . . . in conflict with each other." Caves et al. (1982) demonstrated that "superlative index numbers that maintain circularity and a high degree of characteristicity can be used for making multilateral comparisons."
} 
However, using results from Diewert (1992) for the bilateral Fisher index, ${ }^{5}$ the EKS index can be derived directly from a flexible transformation function that is non-separable in inputs and outputs and permits non-neutral differences in productivity among countries. An example is provided below.

The significance of this result can be stated as follows. As the economic approach determines relationships between economic concepts (such as cost, profit, distance and transformation functions) and index-number formulae, the more general the properties of the functional form in terms of the technology that it can represent, the stronger the theoretical justification for the corresponding index-number formula. Thus, the result provides not only "some economic foundations", but also strong foundations in the sense that the underlying technology that the EKS index corresponds with is very general. Even if this is not the true technology, it is "flexible" and general enough to approximate the true technology closely.

Hence, the EKS index should no longer be overlooked in favor of the CCD index on the basis of economic justification. In addition, it is hoped that this will provide more support for its use over the Geary-Khamis method which is exact for only a linear aggregator function (Diewert, 1999).

\section{EXAMPLE: OUTPUT COMPARISONS}

The EKS multilateral output index can be expressed as follows:

$$
\prod_{s=1}^{S}\left(\frac{Q_{F}\left(p^{s}, p^{k}, y^{s}, y^{k}\right)}{Q_{F}\left(p^{s}, p^{l}, y^{s}, y^{l}\right)}\right)^{1 / S},
$$

where $p^{s}$ denotes the price vector for country $s, y^{s}$ is the corresponding quantity vector, $p^{s} \cdot y^{s}=\sum_{n=1}^{N} p_{n}^{s} y_{n}^{s}$, and $Q_{F}\left(p^{s}, p^{k}, y^{s}, y^{k}\right)$ is the bilateral Fisher quantity index between country $k$ and country $s, s=1, \ldots, S$, given by

$$
Q_{F}\left(p^{s}, p^{k}, y^{s}, y^{k}\right)=\left(\frac{p^{s} \cdot y^{k}}{p^{s} \cdot y^{s}} \cdot \frac{p^{k} \cdot y^{k}}{p^{k} \cdot y^{s}}\right)^{1 / 2} \text {. }
$$

Similarly for $Q_{F}\left(p^{s}, p^{l}, y^{s}, y^{l}\right)$. We will show that the EKS index in (1) can be expressed in terms of transformation functions. Further, the particular functional form for the transformation functions will be flexible, non-separable in inputs and outputs and will permit non-neutral differences in productivity among countries.

Following Caves et al. (1982), a transformation function is taken as a representation of some globally regular technology:

$$
F^{s}\left(y^{s}, x^{s}\right)=1,
$$

where the economic entity $s$ uses the vector of $M$ inputs $x^{s}$ to produce the vector of $N$ outputs $y^{s}$. The specification of the transformation function in (3) indicates that the structure of production can differ in a non-neutral fashion across countries.

${ }^{5}$ Besides Diewert (1992), other authors who have recently strengthened the theoretical case for the use of the bilateral Fisher index formula for productivity measurement include Färe and Grosskopf (1992) and Balk (1993). 
To compare output between countries $k$ and $l$, either country $k$ or $l$ can be used as the base country. If country $l$ is used as the base, then $F^{k}\left(\delta_{l} y^{l}, x^{k}\right)=1$, so that the output of $k$ relative to $l$ is the maximum possible proportional increase $\left(\delta_{l}\right)$ in the elements of the output vector $y^{l}$ given inputs and productivity levels of country $k$. If country $k$ is the base, then $F^{l}\left(y^{k} / \delta_{k}, x^{l}\right)=1$, so that the output of $k$ relative to $l$ is the minimum possible proportional decrease $\left(\delta_{k}\right)$ in the elements of the output vector $y^{k}$ given inputs and productivity levels of country $l$.

Theorem 1 Let $Q_{F}\left(p^{l}, p^{k}, y^{l}, y^{k}\right)$ denote the bilateral Fisher output index, between countries $k$ and $l$. Assuming competitive optimizing behavior and constant returns to scale technology, $\left(p^{s} / p^{s} \cdot y^{s}\right)=\nabla_{y} F^{s}\left(y^{s}, x^{s}\right)$ (Diewert, 1976). Then, in an adaptation of the results of Diewert (1992), the following can be shown:

$$
\begin{aligned}
Q_{F}\left(p^{l}, p^{k}, y^{l}, y^{k}\right) & =\left\{\left[\left(p^{l} / p^{l} \cdot y^{l}\right) \cdot y^{k}\right] /\left[\left(p^{k} / p^{k} \cdot y^{k}\right) \cdot y^{l}\right]\right\}^{1 / 2} \\
& =\left\{\left[y^{k} \cdot \nabla_{y} F^{l}\left(y^{l}, x^{l}\right)\right] /\left[y^{l} \cdot \nabla_{y} F^{k}\left(y^{k}, x^{k}\right)\right]\right\}^{1 / 2} \\
& =F^{k}\left(y^{l}, x^{k}\right)=\delta_{l}=1 / F^{l}\left(y^{k}, x^{l}\right)=\delta_{k},
\end{aligned}
$$

if the transformation function (3) has the following "Diewert" form for countries $s=k, l$ :

$$
F^{s}(x, y)=\sigma^{s}\left[(y \cdot A y)^{-1}(x \cdot C x)+\left(\alpha^{s} \cdot y^{-1}\right)\left(\beta^{s} \cdot x\right)\left(y^{-1} \cdot B^{s} x\right)\right]^{1 / 2},
$$

where $A$ and $C$ are symmetric parameter matrices which are constant across countries, ${ }^{6} B^{s}$ is a parameter matrix, $\sigma^{s}$ is a scalar, $\alpha^{s}$ and $\beta^{s}$ are parameter vectors, $y^{-1}$ is defined to be the vector $\left(y_{1}^{-1}, \ldots, y_{N}^{-1}\right), \sigma^{s}\left[\left(y^{s} \cdot A y^{s}\right)^{-1}\left(x^{s} \cdot C x^{s}\right)\right]^{1 / 2}=1$ and either $(i)$ $B^{k} x^{k}=0_{M},\left(y^{k}\right)^{-1} \cdot B^{k}=0_{N}^{T}, \alpha^{l} \cdot\left(y^{l}\right)^{-1}=0, \beta^{l} \cdot x^{l}=0, \alpha^{k} \cdot\left(y^{l}\right)^{-1} \beta^{k} \cdot x^{l}=0,\left(y^{k}\right)^{-1} \cdot B^{l} x^{k}$ $=0$, or (ii) $B^{l} x^{l}=0_{M},\left(y^{l}\right)^{-1} \cdot B^{l}=0_{N}^{T}, \alpha^{k} \cdot\left(y^{k}\right)^{-1}=0, \beta^{k} \cdot x^{k}=0, \alpha^{l} \cdot\left(y^{k}\right)^{-1} \beta^{l} \cdot x^{k}=0$, $\left(y^{l}\right)^{-1} \cdot B^{k} x^{l}=0 .^{7}$

See the appendix for a proof. Note that the restrictions on the Diewert transformation function imply that $F^{s}\left(x^{s}, y^{s}\right)=1$, as required by (3).

The theorem tells us that the bilateral Fisher output quantity index has an "exact" relationship with the Diewert transformation function. ${ }^{8}$ That is, the Fisher index can be expressed as the transformation function $F^{k}\left(y^{l}, x^{k}\right)$, or equivalently as $1 / F^{l}\left(y^{k}, x^{l}\right)$, if the respective transformation functions have the Diewert form given by (5) and the associated restrictions.

In order to make consistent comparisons between $k, l$ and a third country, $m$, the following circularity property has to hold:

${ }^{6}$ The vectors $y$ and $x$ do not carry a superscript in (5) as they could both have the same superscript or a different superscript depending on the context, e.g. $\left(y^{k}, x^{k}\right)$ or $\left(y^{k}, x^{l}\right)$, as indicated by the restrictions that follow.

${ }^{7}$ This transformation function is flexible at $\left(x^{k}, y^{k}\right)$ under the first set of restrictions, and flexible at $\left(x^{l}, y^{l}\right)$ under the second set of restrictions. The proof of this follows from the proofs in Diewert (1992) for the flexibility of the Diewert revenue function and the Diewert distance function. In addition, it can be verified that this transformation function is non-separable in inputs and outputs and permits non-neutral differences in productivity among countries.

${ }^{8}$ This is similar to the Caves et al. (1982) justification for the use of the translog output quantity index, except that they had to take the geometric mean of their $\delta_{l}$ and $\delta_{k}$ to prove their result. 


$$
\delta_{k l}=\delta_{k m} / \delta_{l m},
$$

where $\delta_{k l}=\delta_{k}=\delta_{l}$ from (4), which measures the difference between the output of country $k$ compared with country $l$. Equation (6) will not necessarily hold if the bilateral Fisher output quantity index is used for comparisons. However, it is possible to modify the definition of output comparisons so that the circularity requirement in (6) is satisfied. This modification yields the EKS multilateral output quantity index.

Let the output of $k$ relative to all countries $s=1, \ldots, S$, be given by the geometric mean of the bilateral comparisons between $k$ and each country $s$ :

$$
\begin{aligned}
\overline{\boldsymbol{\delta}}_{k} & =\left(\prod_{s=1}^{S} \delta_{k s}\right)^{1 / S}=\left(\prod_{s=1}^{S} F^{k}\left(y^{s}, x^{k}\right)\right)^{1 / S}=\left(\prod_{s=1}^{S} F^{s}\left(y^{k}, x^{s}\right)\right)^{-1 / S} \\
& =\prod_{s=1}^{S}\left(Q_{F}\left(p^{s}, p^{k}, y^{s}, y^{k}\right)\right)^{1 / S},
\end{aligned}
$$

where $\delta_{k s}=\delta_{k}=\delta_{s}=Q_{F}(\cdot)$ from (4). Then we can have the following result which establishes a relationship between the Diewert transformation function and the EKS multilateral index.

\section{Result 1}

Using (7), the EKS multilateral output quantity index between countries $k$ and $l, \delta_{k l}^{*}$ is given by:

$$
\begin{aligned}
\delta_{k l}^{*} & =\frac{\bar{\delta}_{k}}{\bar{\delta}_{l}}=\prod_{s=1}^{S}\left(\frac{F^{k}\left(y^{s}, x^{k}\right)}{F^{l}\left(y^{s}, x^{l}\right)}\right)^{1 / S}=\prod_{s=1}^{S}\left(\frac{F^{s}\left(y^{k}, x^{s}\right)}{F^{s}\left(y^{l}, x^{s}\right)}\right)^{-1 / S} \\
& =\prod_{s=1}^{S}\left(\frac{Q_{F}\left(p^{s}, p^{k}, y^{s}, y^{k}\right)}{Q_{F}\left(p^{s}, p^{l}, y^{s}, y^{l}\right)}\right)^{1 / S},
\end{aligned}
$$

where $F(\cdot)$ denotes a transformation function with the Diewert form, as given by (5). It can be easily verified that $\delta_{k l}^{*}$ satisfies (6), so that it satisfies the circularity requirement.

Hence, from the result, we have an answer to CCD - the EKS multilateral output quantity index can be derived from a transformation function which is flexible, non-separable in inputs and outputs and permits non-neutral differences in productivity among countries. See Fox (2000) for similar results for input and productivity comparisons.

\section{APPENDIX}

Proof of Theorem: Using country $l$ as the base, the transformation function is $F^{k}\left(\delta_{y} y^{l}, x^{k}\right)=1=F^{k}\left(y^{k}, x^{k}\right)$. Using equation (5) and the associated restrictions, we have:

$$
F^{k}\left(\delta_{l} y^{l}, x^{k}\right)=\sigma^{k}\left[\left(\delta_{l} y^{l} \cdot A \delta_{l} y^{l}\right)^{-1}\left(x^{k} \cdot C x^{k}\right)\right]^{1 / 2}=1,
$$

and given that (5) exhibits constant returns to scale, we can solve (9) for $\delta_{l \text { : }}$ 


$$
\delta_{l}=\sigma^{k}\left[\left(y^{l} \cdot A y^{l}\right)^{-1}\left(x^{k} \cdot C x^{k}\right)\right]^{1 / 2}=F^{k}\left(y^{l}, x^{k}\right) .
$$

Similarly, using country $k$ as the base, $F^{l}\left(y^{k} / \delta_{k}, x^{l}\right)=1=F^{l}\left(y^{l}, x^{l}\right)$. Using (5), we then have:

$$
F^{l}\left(y^{k} / \delta_{k}, x^{l}\right)=\sigma^{l}\left[\left(y^{k} / \delta_{k} \cdot A y^{k} / \delta_{k}\right)^{-1}\left(x^{l} \cdot C x^{l}\right)\right]^{1 / 2}=1,
$$

and given that (5) exhibits constant returns to scale, we can solve for $\delta_{k}$ :

$$
\delta_{k}=1 / \sigma^{l}\left[\left(y^{k} \cdot A y^{k}\right)^{-1}\left(x^{l} \cdot C x^{l}\right)\right]^{1 / 2}=1 / F^{l}\left(y^{k}, x^{l}\right) .
$$

Consider the square of the bilateral Fisher output index, $Q_{F}(\cdot)$, between countries $k$ and $l$. Using (10) and (12), the derivations in equation (4) then proceed as follows.

$$
\begin{aligned}
Q_{F}\left(p^{l}, p^{k}, y^{l}, y^{k}\right)^{2}= & {\left[\left(p^{l} / p^{l} \cdot y^{l}\right) \cdot y^{k}\right] /\left[\left(p^{k} / p^{k} \cdot y^{k}\right) \cdot y^{l}\right] } \\
= & {\left[y^{k} \cdot \nabla_{y} F^{l}\left(y^{l}, x^{l}\right)\right] /\left[y^{l} \cdot \nabla_{y} F^{k}\left(y^{k}, x^{k}\right)\right] } \\
= & {\left[\left(\sigma^{l}\right)^{2}\left(y^{k} \cdot A y^{l}\right)\left(x^{l} \cdot C x^{l}\right)\left(y^{l} \cdot A y^{l}\right)^{-2}\right] } \\
& /\left[\left(\sigma^{k}\right)^{2}\left(y^{l} \cdot A y^{k}\right)\left(x^{k} \cdot C x^{k}\right)\left(y^{k} \cdot A y^{k}\right)^{-2}\right] \\
= & {\left[\left(\sigma^{l}\right)^{2}\left(y^{l} \cdot A y^{l}\right)^{-1}\left(x^{l} \cdot C x^{l}\right)\left(y^{l} \cdot A y^{l}\right)^{-1}\right] } \\
& /\left[\left(\sigma^{k}\right)^{2}\left(y^{k} \cdot A y^{k}\right)^{-1}\left(x^{k} \cdot C x^{k}\right)\left(y^{k} \cdot A y^{k}\right)^{-1}\right] \\
= & \left(y^{k} \cdot A y^{k}\right)\left(y^{l} \cdot A y^{l}\right)^{-1} \\
= & {\left[\left(\sigma^{k}\right)^{2}\left(y^{l} \cdot A y^{l}\right)^{-1}\left(x^{k} \cdot C x^{k}\right)\right] /\left[\left(\sigma^{k}\right)^{2}\left(y^{k} \cdot A y^{k}\right)^{-1}\left(x^{k} \cdot C x^{k}\right)\right] } \\
= & F^{k}\left(y^{l}, x^{k}\right)^{2} \\
= & \left(\delta_{l}\right)^{2} \\
= & \left(y^{k} \cdot A y^{k}\right)\left(y^{l} \cdot A y^{l}\right)^{-1} \\
= & {\left[\left(\sigma^{l}\right)^{2}\left(y^{l} \cdot A y^{l}\right)^{-1}\left(x^{l} \cdot C x^{l}\right)\right] /\left[\left(\sigma^{l}\right)^{2}\left(y^{k} \cdot A y^{k}\right)^{-1}\left(x^{l} \cdot C x^{l}\right)\right] } \\
= & 1 / F^{l}\left(y^{k}, x^{l}\right)^{2} \\
= & \left(\delta_{k}\right)^{2} .
\end{aligned}
$$

Fox (2000) uses the same (transformation) function to derive the bilateral Fisher input and productivity indexes, whereas Diewert (1992) used different functions in each case.

\section{REFERENCES}

Aczél, J., "Determining Merged Relative Scores," Journal of Mathematical Analysis and Applications, $150,20-40,1990$.

Balk, B. M., "Malmquist Productivity Indexes and Fisher Ideal Indexes: Comment," Economic Journal, 103, 680-2, 1993.

- Industrial Price, Quantity, and Productivity Indices: The Micro-Economic Theory and an Application, Kluwer Academic Publishers, Boston/Dordrecht/London, 1998.

Caves, D. W., L. R. Christensen, and M. W. Tretheway, "U.S. Trunk Air Carriers, 1972-1977: 
A Multilateral Comparison of Total Factor Productivity," in T. G. Cowing and R. E. Stevenson (eds), Productivity Measurement in Regulated Industries, Academic Press, New York, 1981.

Caves, D. W., L. R. Christensen, and W. E. Diewert, "Multilateral Comparisons of Output, Input, and Productivity Using Superlative Index Numbers," Economic Journal, 92, 73-86, 1982.

Coelli, T., D. S. Prasada Rao, and G. E. Battese, An Introduction to Efficiency and Productivity Analysis, Kluwer Academic Publishers, Boston/Dordrecht/London, 1998.

Diewert, W. E., "Exact and Superlative Index Numbers," Journal of Econometrics, 4, 115-45, 1976.

-, "Fisher Ideal Output, Input and Productivity Indexes Revisited," Journal of Productivity Analysis, 3, 211-48, 1992.

- "Axiomatic and Economic Approaches to International Comparisons," in A. Heston and R. E. Lipsey (eds), International and Interarea Comparisons of Income, Output and Prices, Chicago University Press, NBER, Chicago, 1999.

Dowrick, S. and J. Quiggin, "True Measures of GDP and Convergence," American Economic Review, 87, 41-64, 1997.

Drechsler, L. "Weighting of Index Numbers in Multilateral International Comparisons," Review of Income and Wealth, 19, 17-34, 1973.

Eltetö, Ö. and P. Köves, "One Index Computation Problem of International Comparisons," (in Hungarian), Statisztikai Szemle, 42, 507-18, 1964, 1973.

Färe, R. and S. Grosskopf, "Malmquist Productivity Indexes and Fisher Ideal Indexes," Economic Journal, 102, 158-60, 1992.

Fisher, I., The Making of Index Numbers, Houghton-Mifflin, Boston, 1922.

Fox, K. J., "An Economic Justification for the EKS Multilateral Index," School of Economics, University of New South Wales Discussion Paper 2000/3, 2000. Available at: www.economics.unsw.edu.au/research/dp/Dp-2000-03.pdf

Geary, R. G., "A note on Comparisons of Exchange Rates and Purchasing Power between Countries," Journal of the Royal Statistical Society A, 97-9, 1958.

Heston, A. and R. E. Lipsey, "Introduction," in A. Heston and R. E. Lipsey (eds), International and Interarea Comparisons of Income, Output and Prices, Chicago University Press, NBER, Chicago, 1999.

Hill, R. J., "A Taxonomy of Multilateral Methods for Making International Comparisons of Prices and Quantities," Review of Income and Wealth, 43(1), 49-69, 1997.

Khamis, S. H., "A New System of Index Numbers for National and International Purposes," Journal of the Royal Statistical Society A, 96-121, 1972.

Konüs, A. A., English translation, titled "The Problem of the True Index of the Cost of Living," 1924 (published in 1939 in Econometrica 7, 10-29).

Kravis, I. B., R. Summers, and A. Heston, United Nations International Comparisons Project: Phase II, International Comparison of Real Product and Purchasing Power, Johns Hopkins University Press, Baltimore, 1978.

Neary, J. P., "True Multilateral Indexes for International Comparisons of Real Income," www.ucd.ie/economic/staff/pneary/pdf/gaia.pdf, 2000.

Pilat, D. and D. S. Prasada Rao, "Multilateral Comparisons of Output, Productivity, and Purchasing Power Parities in Manufacturing," Review of Income and Wealth, 42, 113-30, 1996.

Szulc, B. "Indices for Multiregional Comparisons," (in Polish), Przeglad Statystyczny, 3, 239-54, 1964.

Törnqvist, L., "The Bank of Finland's Consumption Price Index," Bank of Finland Monthly Bulletin, $10,1-8,1936$.

Walsh, C. M., The Measurement of General Exchange Value, Macmillan, New York, 1901.

, "The Best Form of Index Number: Discussion," Quarterly Publication of the American Statistical Association, 17 (March), 537-44, 1921.

, "Professor Edgeworth's View on Index-Numbers," Quarterly Journal of Economics, 38, 500-19, 1924. 